\title{
An empirical analysis of Cambodian behavior intention towards mobile payment
}

\author{
Nam Hung Do ${ }^{a^{*}}$, Jacquline Thama, Abdol Ali Khatibi ${ }^{\text {a }}$ and S. M. Ferdous Azam ${ }^{a}$
}

${ }^{a}$ Management and Science University (MSU), Malaysia

\begin{tabular}{l}
\hline C H R O N I C L E \\
\hline Article history: \\
Received: June 12, 2019 \\
Received in revised format: June \\
292019 \\
Accepted: July 6, 2019 \\
Available online: \\
July 6, 2019 \\
\hline Keywords: \\
Mobile payment (m-payment) \\
Perceived transaction speed \\
Performance expectancy \\
Effort expectancy \\
Behavior intention
\end{tabular}

\section{Introduction}

Mobile payment refers to the capability of making payment electronically and it is positioned as successful application to electronic commerce (Carr, 2008). Global non-cash payment was grown nearly $10 \%$, from US $\$ 332$ billion in 2012 to US\$483 billion in 2016, in which North America and Europe consume the largest share in total transaction value (Capgemini., 2018). A significant trend in global non-cash payment captures the highest compound annual growth rate of emerging Asia and it was stood at $31 \%$ during the period of 2012-2016. It is expected that global non-cash payment will reach US\$1 trillion in 2019 (The Statistics Portal., 2019). The appearance of mobile payment is particularly important for developing countries where the financial accessibility is still lower than the developed countries. It is reported that more than half of global population are living under poverty conditions and they are unable to access formal financial system and therefore cannot access to affordable financial services (Pelletier et al., 2017; Beck et al., 2008; Beck and Cull, 2013). Moreover, empirical evidences indicate

\footnotetext{
* Corresponding author.

E-mail address: hungdn999@gmail.com (N. H. Do)

\begin{abstract}
Mobile payment is becoming an evitable trend in the globe and is well expanding rapidly into an important fact which decides the level of using mobile payment among users. The existing research models have made empirical evidences confirming behavior intention depended on performance and effort expectancy. This research expands previous empirical evidence by involving perceived transaction speed as an important explanatory variable to both performance expectancy pectancy and effort expectancy among Cambodian users. A total of 200 questionnaires were collected, analyzed and summarized for this study. Result reveals that performance expectancy and effort expectancy affect positively and significantly on behavior intention. Perceived transaction does not have any positive and significant relationship with performance expectancy. Result from this study also concludes the role of perceived transaction speed which is affecting intention to use mobile payment among users. However, there are some limitations to be addressed for the future researches; this research may include larger samples to find out the clear effect on behavior inten-
\end{abstract} C 2019 by the authors; licensee Growing Science, Canada 
that the lack of participation into formal financial services push the people to poorer situation and they cannot smooth income and spend over the time since the cost of informal financial services is too high and risky (Azam \& Imai, 2009; Collins et al., 2009). The issues are addressed by the adoption of mobile payment system (Dodgson et al., 2015). The viable role of mobile payment system is that it delivers formal financial services to wider population and it is considered as cheap and secure way of transferring and storing money (Jack \& Suri, 2014). Cambodia is geographically located in South East Asia. The country's economy has been transforming strongly for the last two decades that bring the country from poor country to a lower-middle income country (The World Bank., 2018). In 2017, Cambodia reached gross national income (GNI) per capita of US \$1,230 and average gross domestic product (GDP) growth rate was more than 7\% during the period of 1995-2017 while poverty rate was significantly decreased from nearly 50\% in 2007 to less than 14\% in 2014 (The World Bank., 2019). However, Cambodia has been still facing some challenges that are limiting further social-economic development. One of the issues is associated with low financial services penetration since only $22 \%$ of Cambodian adults own banking account. Low financial services penetration is audited through the gap value between financial services needs and formal financial supplies is more than US\$24 billion (Mekong Business Initiative, 2018). Such situations encourage the development of mobile payment in this country (Seng \& Lay, 2018). Regarding to academic sciences, there are not so many empirical evidences about how the customers' behavior intention towards mobile payment in Cambodia. In fact, studying the customers' behavior intention towards mobile payment is important and its determinants is important because it helps to widespread mobile payment system and technologies at faster rate (Aslam et al., 2017).

This research is developed with the main objective of identifying the determinants of behavior intention towards mobile payment among Cambodian users. The second section demands for the exploration of the related literatures and the third section aims to propose research model with respective hypotheses. The fourth section discusses about what research method used in the research, how to collect relevant data, and sampling. Empirical analyses are performed and presented in the fifth section before the sixth section links the main findings with previous empirical results. The last section is concluding remarks and it provides the provision of future researches.

\section{Literature Survey}

Mobile payment is defined as a payment which is made by the users through their wireless devices such as smartphones (Bezhovski, 2016). Similarly, mobile payment is acknowledged as the situation of taking advantage from information and communication technologies and making payments of products and services through mobile devices of users (Aydin \& Burnaz, 2016). Recent development of technologies related to mobile payment introduces digital money, digital receipts, and digital coupons, bringing more flexibility in mobile payment (Doan, 2014; Husson, 2015). Mobile payment is very populated in U.S. and Europe but the trend of adopting mobile payment is widespread to emerging economies such as China and India. Mobile payment is treated as important initiative to further improve socio-economic development in some countries such as Canada, Australia, China Mainland and Hong Kong, Singapore and U.K (Ernst \& Young., 2018).

Since mobile payment is emerged as new information technology, several models which were developed to explore user's behavior intention towards new information technology, including Unified Theory of Acceptance and Use of Technology (UTAUT), Technology Acceptance Model (TAM) and Diffusion of Innovation (DOI) (Raina, 2015; Yeh \& Tseng, 2017). Previous researchers preferred using TAM model to understand behavior intention towards mobile payment; this, however, are not limited the growing number of researchers to apply UTAUT model in their research field. UTAUT employs four determinants of users' behavior intention, including social influences, effort expectancy, facilitating condition, and performance expectancy (Liebana-Cabanillas et al., 2017; Kumar et al., 2018). The revised version of UTAUT model initiates additional determinants, namely price value, users' habit, and hedonic value. It is asserted that UTAUT model is better than previous model in terms of explanatory power (Venkatesh 
et al., 2003, 2012). UTAUT model plays a key role in the academic sciences about technology acceptance of users and it helps to explain why users accept or reject particular technology (Lai, 2017; Rondan-Catauna et al., 2015; Samaradiwakara \& Gunawardena, 2014). This research does not examine how UTAUT model performs in explaining Cambodian users' behavior intention towards mobile payment. However, this research focuses on two determinants of UTAUT model as performance expectancy and effort expectancy in the relationship with behavior intention. Furthermore, perceived transaction speed is employed into the research to determine how Cambodian users perceive about the speed of transaction through mobile payment. In the next section, research model is proposed along with respective hypotheses. It comprises the collection of previous empirical results related to proposed hypotheses.

\section{Research Model and Hypothesis}

The research model is depicted in Fig. 1 below:

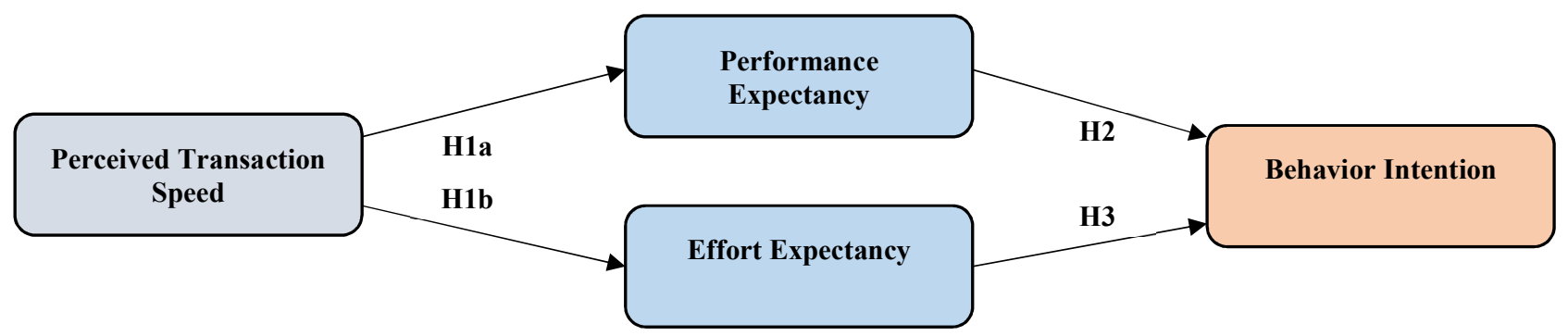

Fig.1. Research model

Fig. 1 dictates a causal relationship between perceived transaction speed, performance expectancy, effort expectancy, and behavior intention. In more detail, behavior intention is explained by performance expectancy and effort expectancy. The research model examines how perceived transaction speed influences on performance expectancy and effort expectancy. Given to that, there are hypotheses which are proposed from chosen research model.

\subsection{Perceived Transaction Speed}

Perceived transaction speed is defined as time required for a transaction is taken or how many transactions to be taken for a certain time span (Seetharaman et al., 2017). Perceived transaction speed is also viewed as a necessary time to make a transaction through a mobile device (Abadzhmarinova, 2014). Perceived usefulness is measured by perceived transaction convenience and speed (Chen et al., 2018). Transaction speed is measured through time of payment and time of providing notification in accordance with the change of account balance (Schuh \& Stavins, 2016). A survey with 88 mobile phone users in Mexico highlights that perceived transaction speed is essential factor in mobile payment (Chiang et al., 2017). A research paper confirms that perceived transaction speed has positive and significant relationship with performance expectancy and effort expectancy (Teo et al., 2015). Thus, two hypotheses are proposed below:

H1a: Perceived transaction speed affects positively and significantly performance expectancy.

H1b: Perceived transaction speed affects positively and significantly effort expectancy.

\subsection{Performance Expectancy}

Performance expectancy is defined as a degree of job performance is achieved and improved by using an innovative technology (Sair \& Danish, 2018). It is perceived as the benefits that user can receive from using a technology to perform certain tasks and is considered as the most robust and powerful explanatory variable in predicting behavior intention towards a technology (Palau-Saumell et al., 2019). The 
effect of performance expectancy on behavior intention towards mobile applications and mobile payment are affirmed in some previous empirical evidences (Lai, 2013; Okumus et al., 2015; Slade et al., 2015). A research paper confirms the positive and significant effect of performance expectancy on mobile payment acceptance of Chinese users (Wang \& Li, 2012). Similarly, Dimitrii (2018) found positive and significant effect of performance expectancy on behavior intention of using mobile wallet among Russian users. However, positive and significant effect of performance expectancy on behavior intention towards mobile payment seems not consistent across previous empirical evidences. A research paper which was developed to explored WeChat mobile payment in China identified that performance expectancy does not affect significantly on user's behavior intention (Havidz et al., 2018). Thus, the second hypothesis is proposed below:

$\mathrm{H}_{2}$ : Performance expectancy affects positively and significantly on behavior intention.

\subsection{Effort Expectancy}

Effort expectancy is defined as how the users feel easiness when they use a particular system (Al-Azizi et al., 2018). It is associated with the complexity level perceived by users when they use an information technology system or a mobile-based application (Qi, 2018). This factor is used as explanatory variable to explain behavior intention towards mobile communication technologies among commercial farmers in Uganda (Moya et al., 2018). A research paper indicated that the effect of effort expectancy to behavior intention to use mobile payment is significant in Morocco (Lafraxo et al., 2018). Other research paper confirmed positive and significant relationship between effort expectancy and behavior intention of mobile payment in Vietnam (Bui \& Bui, 2018). However, a research paper collected the data from 30 Portuguese mobile payment users and they did not obtain significant effect of effort expectancy on behavior intention (Oliveira et al., 2016). Thus, the third hypothesis is proposed below:

$\mathrm{H}_{3}$ : Effort expectancy affects positively and significantly on behavior intention.

\section{Research Methodology}

Quantitative research method is employed in this study in order to verify the proposed hypotheses given in the previous section. It requires the variables to be measurable, leading to the variable operationalization. Likert scale is utilized to capture users' evaluations and a scale of 5 points is chosen. The point value is ranged from 1 to 5 with 1 as strongly disagree and 5 as strongly agree. The third point in this Likert scale measures neutral attitude from the respondents and it reflects the attitude of neither agreed nor disagreed towards a statement of the users.

The operationalization of perceived transaction speed is taken from a research study with six measurement items (Abadzhmarinova, 2014). The operationalization of performance expectancy is taken from numerous research journals and it is measured by seven items (Gefen \& Straub, 2000; Schierz et al., 2010; de Luna et al., 2017; Liebana-Cabanillas et al., 2017). The operationalization of effort expectancy is measured by seven items taken from some researches (Zhou, 2013; Foon, 2014; Musa et al., 2015). Finally, behavior intention factor is operationalized by seven items which are used in many studies.

The questionnaire was prepared and delivered by hand to Cambodian users who have been using mobile payment services. Currently, mobile payment services in Cambodia are provided by many players such as True Money, Pi Pay, etc. A Cambodian user is selected into the survey if this user is being used mobile services provided by available providers in the country and this user actually made at least one mobile payment over the last three months. Convenient sampling is selected to choose the member from the population of Cambodian users who are using mobile payment services. The survey will ended right after a total of 200 questionnaires are collected successfully. After the data was collected, it was put into SPSS and AMOS software to further perform empirical analyses. The result of empirical analyses will be presented in the following section. 


\section{Empirical Analysis}

After data cleansing, descriptive statistics, reliability test, and exploratory factor analysis (EFA) were conducted by using SPSS software. The evaluation of research model and hypotheses testing were confirmed by using AMOS software.

\subsection{The characteristics of the respondents}

The characteristics of 200 respondents are captured through variables in this studies that reflect mobile payment services in Cambodia and results obtained are presented in Table 1. General information related to mobile payment usage of Cambodian users includes mobile payment provider, purpose of using mobile payment, and the frequencies of using mobile payment.

\section{Table 1}

Payment usage description

\begin{tabular}{|c|c|c|c|}
\hline Variable & Characteristics & Frequency & Percent \\
\hline \multirow{7}{*}{ M-payment provider } & True Money & 8 & 4.0 \\
\hline & Pi Pay & 12 & 6.0 \\
\hline & E-cash & 5 & 2.5 \\
\hline & Emoney & 139 & 69.5 \\
\hline & SmartLuy & 4 & 2.0 \\
\hline & Wing & 32 & 16.0 \\
\hline & Total & 200 & 100.0 \\
\hline \multirow{4}{*}{ Purpose of using M-payment } & Pay bills & 118 & 59.0 \\
\hline & Transfer money & 62 & 31.0 \\
\hline & Purchasing products/services online & 20 & 10.0 \\
\hline & Total & 200 & 100.0 \\
\hline \multirow{5}{*}{ How many time of using m-payment } & One mobile payment transaction & 8 & 4.0 \\
\hline & Two mobile payment transactions & 36 & 18.0 \\
\hline & Three mobile payment transactions & 65 & 32.5 \\
\hline & More than three mobile payment transactions & 91 & 45.5 \\
\hline & Total & 200 & 100.0 \\
\hline
\end{tabular}

Currently, mobile payment services are provided by both local and foreign-based companies in Cambodia. This study shows that majority of the respondents have been using mobile payment through Emoney platform (139 respondents, 69.56\%), followed by Wings (32 respondents, 16.0\%).

\section{Table 2}

Demographic Description

\begin{tabular}{|c|c|c|c|}
\hline Variable & Characteristics & Frequency & Percent \\
\hline \multirow{3}{*}{ Gender } & Male & 148 & 74.0 \\
\hline & Female & 52 & 26.0 \\
\hline & Total & 200 & 100.0 \\
\hline \multirow{8}{*}{ Age } & Less than 20 & 9 & 4.5 \\
\hline & $21-25$ & 78 & 39.0 \\
\hline & $26-30$ & 77 & 38.5 \\
\hline & $31-35$ & 27 & 13.5 \\
\hline & $36-40$ & 5 & 2.5 \\
\hline & $41-45$ & 3 & 1.5 \\
\hline & $46-50$ & 1 & .5 \\
\hline & Total & 200 & 100.0 \\
\hline \multirow{4}{*}{ Education } & High school and below & 17 & 8.5 \\
\hline & Bachelor & 151 & 75.5 \\
\hline & Master & 32 & 16.0 \\
\hline & Total & 200 & 100.0 \\
\hline \multirow{3}{*}{ Marital status } & Single & 156 & 78.0 \\
\hline & Married & 44 & 22.0 \\
\hline & Total & 200 & 100.0 \\
\hline \multirow{5}{*}{ Occupation } & Professional & 157 & 78.5 \\
\hline & Management & 20 & 10.0 \\
\hline & Student & 6 & 3.0 \\
\hline & Self-employed & 17 & 8.5 \\
\hline & Total & 200 & 100.0 \\
\hline \multirow{5}{*}{ Monthly income } & Less than 1 million Riel & 9 & 4.5 \\
\hline & $1-3$ million Riel & 51 & 25.5 \\
\hline & 3-5 million Riel & 93 & 46.5 \\
\hline & More than 5 million Riel & 47 & 23.5 \\
\hline & Total & 200 & 100.0 \\
\hline
\end{tabular}


There are other mobile payment service providers in Cambodia such as True Money ( 8 respondents, 4.0\%), Pi Pay (12 respondents, 6.0\%), ABA Bank: e-cash (5 respondents, 2.5\%), and SmartLuy (4 respondents, $2.0 \%$ ). Furthermore, Cambodian users use mobile payment mainly for bill payment (118 respondents, $59.0 \%$ ) and money transfer (62 respondents, $31.0 \%$ ) and only a small proportion of users use mobile payment to purchase products and services online (20 respondents, $10.0 \%)$. It is found in this study that Cambodian are frequent users of mobile payment services, showing more than $70 \%$ of total respondents have been using mobile payment services for more than three times (156 respondents, 78.0\%). Demographic variables (gender, age, education, marital status, occupation, and household monthly income). Obtained result is presented in Table 2. The survey was participated by 200 respondents in which 148 respondents are male and 52 respondents are female. The domination of male respondents against female respondents. The survey also captures the age of 200 respondents and the result shows that $82.0 \%$ of total respondents age less than 30 years old. Highest number of respondents is belonged to 21-25 age group (78 respondents, 39.0\%). Mobile payment services are usable when users have smartphones and therefore it attracts to younger group while older group is more preferable to features phones. Mobile payment services gain higher attention from single people in Cambodia, showing through higher number of respondents who are single and have been using mobile payment services (156 respondents, $78.0 \%$ ). Occupation of the respondents is explored and there are 157 professionals who were participated into the survey while the numbers of respondents who were holding management position, students, and self-employed are 20 people, 6 people, and 17 people respectively. Finally, monthly income of the respondents is further explored and it is showing that only 9 respondents $(4.5 \%)$ have monthly income less than 1 million Riel, 51 respondents $(25.5 \%)$ have monthly income of $1-3$ million Riel, 93 respondents (46.5\%) have monthly income of 3-5 million Riel, and 47 respondents $(23.5 \%)$ have monthly income of more than 5 million Riel.

\subsection{Descriptive statistics}

Descriptive statistics provide mean value of each item used in the questionnaire. Obtained result of descriptive statistics is presented in Table 3:

\section{Table 3}

Descriptive statistics

\begin{tabular}{|c|c|c|c|c|c|}
\hline Item & $\mathrm{N}$ & Minimum & Maximum & Mean & Std. Deviation \\
\hline PE1 & 200 & 1 & 5 & 2.935 & 1.094 \\
\hline PE2 & 200 & 1 & 5 & 3.165 & 0.955 \\
\hline PE3 & 200 & 1 & 5 & 3.125 & 1.065 \\
\hline PE4 & 200 & 1 & 5 & 2.880 & 1.101 \\
\hline PE5 & 200 & 1 & 5 & 3.000 & 1.165 \\
\hline PE6 & 200 & 1 & 5 & 2.805 & 1.146 \\
\hline PE7 & 200 & 1 & 5 & 3.140 & 0.851 \\
\hline PE8 & 200 & 1 & 5 & 3.160 & 0.916 \\
\hline PE9 & 200 & 1 & 5 & 3.130 & 0.999 \\
\hline EE1 & 200 & 1 & 5 & 3.365 & 0.925 \\
\hline EE2 & 200 & 1 & 5 & 3.130 & 1.058 \\
\hline EE3 & 200 & 1 & 5 & 3.115 & 1.126 \\
\hline EE4 & 200 & 1 & 5 & 3.355 & 0.961 \\
\hline EE5 & 200 & 1 & 5 & 3.420 & 0.876 \\
\hline EE6 & 200 & 1 & 5 & 3.620 & 1.105 \\
\hline EE7 & 200 & 1 & 5 & 3.380 & 0.949 \\
\hline PTS1 & 200 & 1 & 5 & 3.500 & 1.032 \\
\hline PTS2 & 200 & 1 & 5 & 3.520 & 1.017 \\
\hline PTS3 & 200 & 1 & 5 & 3.330 & 1.066 \\
\hline PTS4 & 200 & 1 & 5 & 3.430 & 1.136 \\
\hline PTS5 & 200 & 1 & 5 & 3.345 & 1.054 \\
\hline PTS6 6 & 200 & 1 & 5 & 3.345 & 1.005 \\
\hline PTS7 & 200 & 1 & 5 & 3.475 & 1.017 \\
\hline BI1 & 200 & 1 & 5 & 2.515 & 0.796 \\
\hline BI2 & 200 & 1 & 5 & 2.520 & 0.997 \\
\hline BI3 & 200 & 1 & 5 & 2.530 & 0.972 \\
\hline BI4 & 200 & 1 & 5 & 2.390 & 0.849 \\
\hline BI5 & 200 & 1 & 5 & 3.510 & 1.017 \\
\hline BI6 & 200 & 1 & 5 & 3.245 & 0.811 \\
\hline BI7 & 200 & 1 & 5 & 2.520 & 1.002 \\
\hline BI8 & 200 & 1 & 5 & 2.465 & 0.950 \\
\hline BI9 & 200 & 1 & 5 & 3.255 & 0.757 \\
\hline
\end{tabular}

In terms of performance expectancy, there are 9 items and they are coded as from PE1 to PE9. Mean values of PE1, PE2, PE3, PE4, PE5, PE6, PE7, PE8, and PE9 are 2.935, 3.165, 3.125, 2.880, 3.000, 
$2.805,3.140,3.160$, and 3.130, respectively. None of performance expectancy's items has mean values more than 3.5 or less than 2.5, indicating that Cambodian users neither agreed nor disagreed with the statements of items. In terms of effort expectancy, there are 7 items and they are coded as from EE1 to EE7. Mean values of EE1, EE2, EE3, EE4, EE5, EE6, and EE7 are 3.365, 3.130, 3.115, 3.355, 3.420, 3.620 , and 3.380, respectively. It is emphasized that only EE6 has mean value more than 3.5 and other items have mean values less than 3.5 and higher than 2.5. It is concluded that the respondents agree with the statement of the interaction with m-payment system would be clear and understandable. Others neither agreed nor disagreed with all other statements of effort expectancy towards mobile payment. In terms of perceived transaction speed, there are 7 items and they are coded as from PTS1 to PTS7. Mean values of PTS1, PTS2, PTS3, PTS4, PTS5, PTS6, and PTS7 are 3.500, 3.520, 3.330, 3.430, 3.345, 3.345, and 3.475, respectively. Only PTS1 and PTS2 have mean value from 3.5. It means that the respondents agree with the statements of using mobile payment will be convenient and will be hassle-free. Other respondents neither agreed nor disagreed with other statements. In terms of behavior intention, there are 9 items and they are coded as from BI1 to BI9. Mean values of BI1, BI2, BI3, BI4, BI5, BI6, BI7, BI8, and BI9 are 2.515, 2.520, 2.530, 2.390, 3.510, 3.245, 2.520, 2.465, and 3.255, respectively. Herein, BI4 and BI8 have mean values less than 2.5, indicating that the respondents disagreed with the statements of they will strongly recommend others to use mobile payment systems and they will educate others to use mobile payment. BI5 has mean value more than 3.5 and the respondents agreed that they would not hesitate to provide personal information to mobile payment service. Other items have mean values between 2.5 and 3.5 and it means that the respondents neither agreed nor disagreed with all other items' statements.

\subsection{Reliability analysis}

Reliability test is conducted to check the internal consistency between items of a factor. It requires to calculate Cronbach's alpha and two additional indicators, namely Corrected item-total correlation and Cronbach's alpha if item deleted.

\section{Table 4}

Reliability test analysis

\begin{tabular}{|c|c|c|c|c|}
\hline Factor & Code & Cronbach's alpha & Corrected item-total correlation & Cronbach's alpha if item deleted \\
\hline \multirow{9}{*}{$\begin{array}{l}\text { Performance } \\
\text { expectancy }\end{array}$} & PE1 & \multirow{9}{*}{0.897} & 0.749 & 0.879 \\
\hline & PE2 & & 0.748 & 0.880 \\
\hline & PE3 & & 0.533 & 0.896 \\
\hline & PE4 & & 0.745 & 0.879 \\
\hline & PE5 & & 0.615 & 0.891 \\
\hline & PE6 & & 0.584 & 0.893 \\
\hline & PE7 & & 0.772 & 0.880 \\
\hline & PE8 & & 0.715 & 0.883 \\
\hline & PE9 & & 0.564 & 0.893 \\
\hline \multirow{7}{*}{ Effort expectancy } & EE1 & \multirow{7}{*}{0.887} & 0.721 & 0.866 \\
\hline & EE2 & & 0.589 & 0.882 \\
\hline & EE3 & & 0.631 & 0.878 \\
\hline & EE4 & & 0.763 & 0.861 \\
\hline & EE5 & & 0.701 & 0.869 \\
\hline & EE6 & & 0.662 & 0.874 \\
\hline & EE7 & & 0.732 & 0.865 \\
\hline \multirow{7}{*}{$\begin{array}{l}\text { Perceived } \\
\text { transaction speed }\end{array}$} & PTS1 & \multirow{7}{*}{0.889} & 0.551 & 0.888 \\
\hline & PTS2 & & 0.725 & 0.867 \\
\hline & PTS3 & & 0.668 & 0.874 \\
\hline & PTS4 & & 0.684 & 0.873 \\
\hline & PTS5 & & 0.759 & 0.863 \\
\hline & PTS6 & & 0.775 & 0.861 \\
\hline & PTS7 & & 0.623 & 0.879 \\
\hline \multirow{9}{*}{$\begin{array}{l}\text { Behavior intention to } \\
\text { use mobile payment }\end{array}$} & BI1 & \multirow{9}{*}{0.898} & 0.815 & 0.877 \\
\hline & $\mathrm{BI} 2$ & & 0.604 & 0.892 \\
\hline & $\mathrm{BI} 3$ & & 0.603 & 0.892 \\
\hline & BI4 & & 0.746 & 0.881 \\
\hline & BI5 & & 0.706 & 0.884 \\
\hline & BI6 & & 0.647 & 0.888 \\
\hline & BI7 & & 0.564 & 0.896 \\
\hline & BI8 & & 0.611 & 0.891 \\
\hline & BI9 & & 0.765 & 0.881 \\
\hline
\end{tabular}


The requirement of reliability test is that Cronbach's alpha value is at least 0.7 and corrected item-total correlation value is at least 0.3 . Additionally, when deleting one item, Cronbach's alpha is recalculated and new value must be smaller than Cronbach's alpha value before this item is deleted. Obtained result for performance expectancy, effort expectancy, perceived transaction speed, and behavior intention factors are presented in Table 4. Cronbach's alpha values of performance expectancy, effort expectancy, perceived transaction speed, and behavior intention factor are calculated at $0.897,0.887,0.889$, and 0.898 , respectively and all values are higher than 0.7 . The second step of reliability test is to verify the value of corrected item-total correlation and obtained result shows that all items had this value more than 0.3. Finally, when one item is deleted, new Cronbach's alpha is lower than original Cronbach's alpha. It is concluded that internal consistency between items of factor is satisfied. In addition, none of observed items was deleted because the requirements of reliability test were not violated. The researchers continue to input all items into EFA analysis with the result is presented in the next section.

\subsection{EFA analysis}

EFA analysis requires to calculate KMO and runs Bartlett's test. It generates the components with initial eigenvalues and only component with initial eigenvalue more than 1.0 is selected and selected components must have cumulative \% variance more than $50 \%$. Factor loading of each item is expected higher than 0.5. It is denoted that Varimax is used as rotation technique. EFA analysis is conducted and obtained result is summarized in Table 5.

\section{Table 5}

\section{EFA analysis result after Varimax rotation}

\begin{tabular}{|c|c|c|c|c|c|}
\hline \multicolumn{6}{|c|}{$\mathrm{KMO}=0.804 ;$ Bartlett's test $=4345.084 ; \mathrm{p}$-value $<0.0001$} \\
\hline Component & 1 & 2 & 3 & 4 & \multirow{3}{*}{ Communalities } \\
\hline Initial eigenvalues & 8.759 & 4.435 & 3.258 & 2.747 & \\
\hline$\%$ of variance & 27.370 & 13.860 & 10.182 & 8.583 & \\
\hline PE7 & 0.837 & & & & 0.713 \\
\hline PE4 & 0.815 & & & & 0.672 \\
\hline PE2 & 0.798 & & & & 0.694 \\
\hline PE1 & 0.784 & & & & 0.686 \\
\hline PE8 & 0.781 & & & & 0.643 \\
\hline PE5 & 0.682 & & & & 0.493 \\
\hline PE9 & 0.672 & & & & 0.478 \\
\hline PE6 & 0.636 & & & & 0.449 \\
\hline PE3 & 0.609 & & & & 0.395 \\
\hline BI1 & & 0.885 & & & 0.810 \\
\hline BI4 & & 0.731 & & & 0.632 \\
\hline BI9 & & 0.725 & & & 0.696 \\
\hline $\mathrm{BI} 2$ & & 0.723 & & & 0.542 \\
\hline BI3 & & 0.699 & & & 0.519 \\
\hline BI7 & & 0.681 & & & 0.479 \\
\hline BI8 & & 0.675 & & & 0.493 \\
\hline BI5 & & 0.619 & & & 0.657 \\
\hline BI6 & & 0.597 & & & 0.513 \\
\hline EE7 & & & 0.815 & & 0.678 \\
\hline EE4 & & & 0.809 & & 0.697 \\
\hline EE1 & & & 0.788 & & 0.652 \\
\hline EE6 & & & 0.784 & & 0.631 \\
\hline EE5 & & & 0.766 & & 0.633 \\
\hline EE3 & & & 0.678 & & 0.526 \\
\hline EE2 & & & 0.672 & & 0.477 \\
\hline PTS6 & & & & 0.850 & 0.746 \\
\hline PTS5 & & & & 0.828 & 0.719 \\
\hline PTS2 & & & & 0.767 & 0.636 \\
\hline PTS4 & & & & 0.749 & 0.600 \\
\hline PTS3 & & & & 0.747 & 0.599 \\
\hline PTS7 & & & & 0.745 & 0.585 \\
\hline PTS1 & & & & 0.592 & 0.455 \\
\hline
\end{tabular}

Obtained result from KMO and Bartlett's test confirms that EFA is able to use for the dataset of 200 respondents. KMO value is 0.804 and it is higher than 0.5 while Bartlett's test value is estimated at 4345.084 and p-value less than 0.05. It means that both KMO and Bartlett's test satisfy the pre-test of 
EFA and it confirms this data analysis technique is applicable. There are four components which are extracted with initial eigenvalues more than 1.0 and the cumulative $\%$ variance explained by these components is higher than 50\%. Component 1 has initial eigenvalue of 8.759 and it can explain for $27.370 \%$ of variance. Component 1 includes all items of performance expectancy. Component 2 has initial eigenvalue of 4.435 and it can explain for $13.860 \%$ of variance. Component 2 includes all items of behavior intention. Component 3 has initial eigenvalue of 3.258 and it can explain for $10.182 \%$ of variance. Component 3 includes all items of effort expectancy. Component 4 has initial eigenvalue of 2.747 and it can explain for $8.583 \%$ of variance. Component 4 includes all items of perceived transaction speed. The detail description of each component is explained further below:

- Component 1 includes all items of performance expectancy and factor loading values calculated for PE1, PE2, PE3, PE4, PE5, PE6, PE7, PE8, and PE9 are 0.784, 0.798, 0.609, 0.815, 0.682, 0.636, $0.837,0.781$, and 0.672 , respectively. All factor loading values are higher than 0.5 .

- Component 2 includes all items of behavior intention and factor loading values calculated for $\mathrm{BI} 1, \mathrm{BI}$, BI3, BI4, BI5, BI6, BI7, BI8, and BI9 are 0.885, 0.723, 0.699, 0.731, 0.619, 0.597, 0.681, 0.675 , and 0.725 , respectively. All factor loading values are higher than 0.5 .

- Component 3 includes all items of effort expectancy and factor loading values calculated for EE1, EE2, EE3, EE4, EE5, EE6, and EE7 are 0.788, 0.672, 0.678, 0.809, 0.766, 0.784, and 0.815, respectively. All factor loading values are higher than 0.5 .

- Component 4 includes all items of perceived transaction speed and factor loading values calculated for PTS1, PTS2, PTS3, PTS4, PTS5, PTS6, and PTS7 are 0.592, 0.767, 0.747, 0.749, 0.828, 0.850, and 0.745 , respectively. All factor loading values are higher than 0.5 .

\subsection{Evaluation of research model}

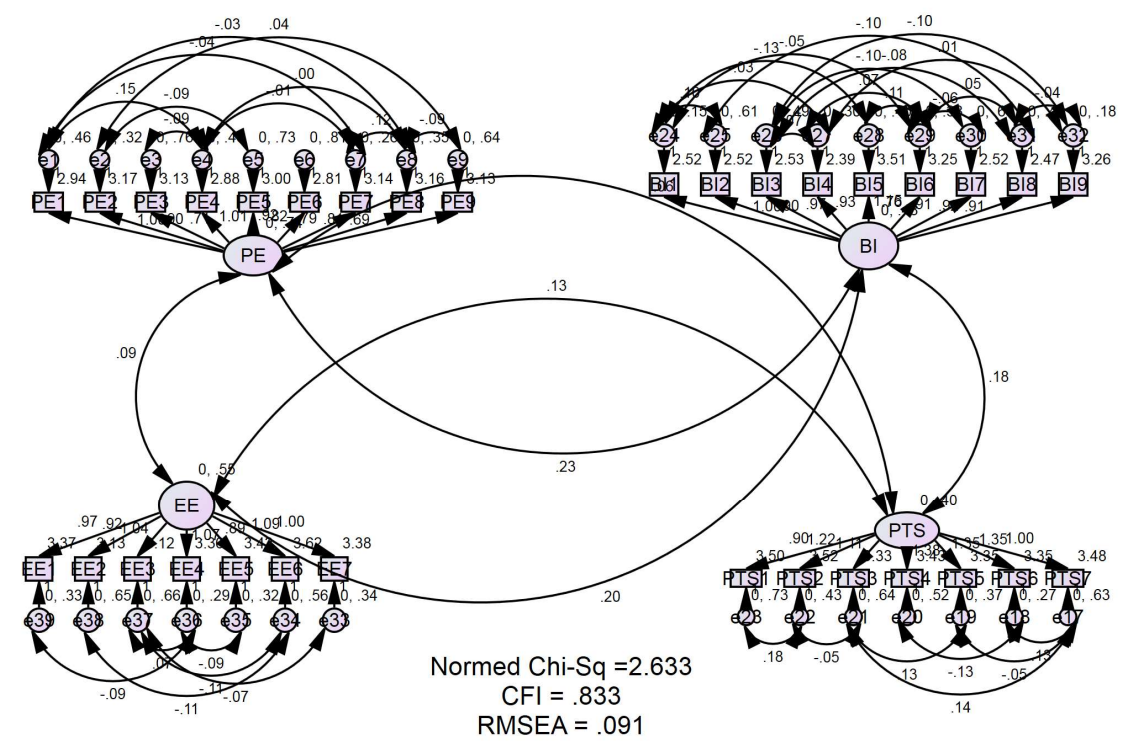

Fig. 2. Confirmatory factor analysis (CFA) of overall Measurement Model

\section{Table 6}

CFA results for Overall Measurement Model

\begin{tabular}{lccc}
\hline Goodness of fit statistics & Initial Model & Modified Model & Threshold value for the fit indices \\
\hline Normed Chi-Square & 2.686 & 2.633 & $<5.0$ \\
CFI & 0.825 & 0.833 & $>0.9$ \\
RMSEA & 0.92 & 0.091 & $<0.08$ \\
\hline
\end{tabular}


To evaluate research model, AMOS is utilized and the output of model fit is presented in Table 6. It is denoted that Chi-square/df (CMIN/DF) is 2.633 and it is lower than 5. CFI value is calculated at 0.833 which is slightly below 0.9 and RMSEA is 0.091. Judging from the fit indices, Normed Chi-Square qualifies the benchmark and suggests a good fit. It is concluded the model is within acceptable fit with the dataset, the model is not only based on statistics but empirical studies need to be also considered (Byrne \& Van de Vijver, 2010; Byrne, 2016). Therefore, the researchers accept its fit model. In the next section, the researcher goes to Structural Model Analysis.

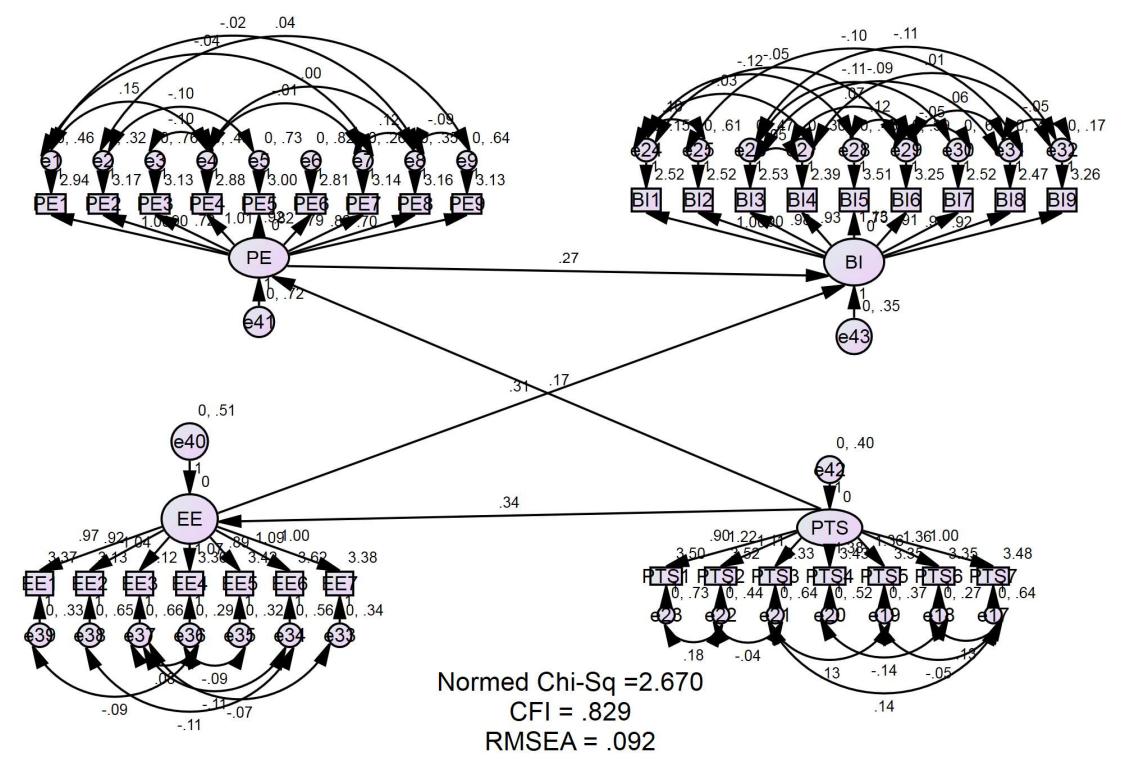

Fig. 3. Confirmatory factor analysis (CFA) of overall Structural Model

Table 7

CFA results for Overall Structural Model

\begin{tabular}{lclc}
\hline \multicolumn{1}{c}{ Goodness of fit statistics } & Initial Model & Modified Model & Threshold value for the fit indices \\
\hline Normed Chi-Square & 2.670 & No Modifications & $<5.0$ \\
CFI & 0.829 & No Modifications & $>0.9$ \\
RMSEA & 0.092 & No Modifications & $<0.08$ \\
\hline
\end{tabular}

It is denoted that Chi-square/df (CMIN/DF) is 2.6703 and it is lower than 5. CFI value is calculated at 0.829 which is slightly below 0.9 and RMSEA is 0.092 . Without modification, Normed Chi-Square qualifies the benchmark and suggests a good fit. It is concluded the model is within acceptable fit with the dataset, the model is not only based on statistics but empirical studies need to be also considered (Byrne, 2016). Therefore, the researchers accept its fit model, and in the next section, the researcher will start the hypothesis testing to verify the said model.

\subsection{Hypothesis testing}

The result of hypothesis testing is presented in Table 8 below:

\section{Table 8}

Hypothesis testing

\begin{tabular}{|c|c|c|c|c|c|c|c|c|}
\hline \multicolumn{4}{|c|}{ Effect } & \multirow{2}{*}{$\frac{\text { Estimate }}{.341}$} & \multirow{2}{*}{$\begin{array}{l}\text { S.E. } \\
.096\end{array}$} & \multirow{2}{*}{$\begin{array}{l}\text { C.R. } \\
3.552\end{array}$} & \multirow{2}{*}{$\frac{\mathrm{P}}{* * *}$} & \multirow{2}{*}{$\begin{array}{l}\text { Results } \\
\text { Accepted }\end{array}$} \\
\hline $\mathrm{H}_{1 \mathrm{~b}}$ & Effort Expectancy & $\leftarrow$ & Perceived Transaction Speed & & & & & \\
\hline $\mathrm{H}_{1 \mathrm{a}}$ & Performance Expectancy & $\leftarrow$ & Perceived Transaction Speed & .167 & .106 & 1.576 & .115 & Rejected \\
\hline $\mathrm{H} 2$ & Behavior Intention & $\leftarrow$ & Performance Expectancy & .270 & .058 & 4.671 & $* * *$ & Accepted \\
\hline $\mathrm{H} 3$ & Behavior Intention & $\leftarrow$ & Effort Expectancy & .315 & .065 & 4.836 & $* * *$ & Accepted \\
\hline
\end{tabular}


$\mathrm{H}_{1 \mathrm{a}}$ indicates that Perceived Transaction Speed does not affect positively and significantly the Performance Expectancy. Coefficient is estimated at 0.167 and p-value is 0.115 and it is more than 0.05 . Therefore, $\mathrm{H}_{1 \mathrm{a}}$ is not accepted.

$\mathrm{H}_{1 \mathrm{~b}}$ indicates that Perceived Transaction Speed affects positively and significantly Effort Expectancy. Coefficient is estimated at 0.341 and $\mathrm{p}$-value is less than 0.05 . Therefore, $\mathrm{H}_{1 \mathrm{~b}}$ is accepted.

$\mathrm{H}_{2}$ indicates that Performance Expectancy affects positively and significantly on Behavior Intention. Coefficient is estimated at 0.270 and p-value is less than 0.05 . Therefore, $\mathrm{H}_{2}$ is accepted.

$\mathrm{H}_{3}$ indicates that Effort Expectancy affects positively and significantly on Behavior Intention. Coefficient is estimated at 0.315 and $p$-value is less than 0.05 . Therefore, $\mathrm{H}_{3}$ is accepted.

\section{Discussion of empirical results}

Obtained empirical results are similar to previous studies. In this study, perceived transaction speed is found in positive and significant relationship with effort expectancy and it is confirmed by Teo et al. (2015). Teo et al. (2015) confirmed that perceived transaction speed affects significantly the performance expectancy and it is also confirmed among Cambodian users. Empirical evidences also confirm the positive and significant effect of performance expectancy and effort expectancy to behavior intention and this finding is aligned with empirical evidences provided in the research papers (Wang \& $\mathrm{Li}, 2012$; Dimitrii, 2018; Moya et al., 2018; Lafraxo, 2018). Fig. 3 below illustrates the relationship between factors and items after SEM is conducted.

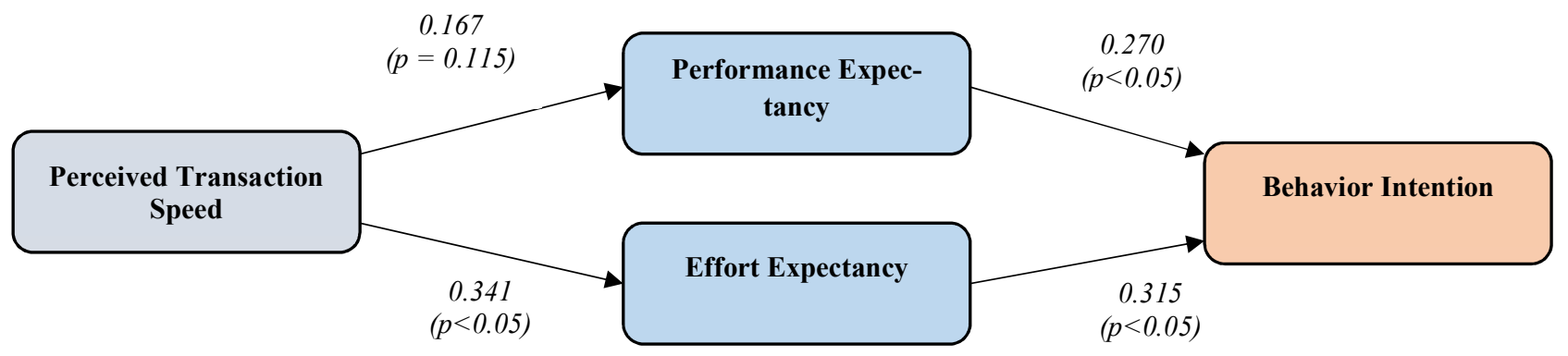

Fig. 4. Model estimation result

\section{Conclusion and future researches}

This research was developed with the main objective of identifying the determinants of behavior intention towards mobile payment among Cambodian users. A research framework was developed in which behavior intention was depended on performance expectancy and effort expectancy. Moreover, the impact of perceived transaction speed is explored regarding to its impact to both performance expectancy and effort expectancy. A data is collected from 200 successful questionnaires with Cambodian users. Empirical result shows that perceived transaction speed impacts significantly and positively on effort expectancy. In addition, both performance expectancy and effort expectancy had significant and positive effects on behavior intention. Based on the summary of key findings, it has denoted that this research model is useful to explain behavior intention of Cambodian users towards mobile payment. Cambodian users will increase their usage towards mobile payment if they perceive that mobile payment is worth their effort and the performance of mobile payment exceeds the users' requirements and demands. In addition, mobile payment services providers in Cambodia must pay attention to the transaction speed as important criterion when the users make transaction through their wireless devices; transaction speed is one of the most concerned factors because they can help users to save time when they do transactions, not to waste time queue in long line to complete the transactions at the bank counter and they can change the Cambodian user's habit to the new payment method which is very popular in developed countries. 
Average time of fulfilling a mobile payment should be as low as possible. The delay will deteriorate the behavior intention towards this payment scheme. This study will help the mobile payment service providers find out the smart solutions to satisfy the users' demand, especially to determine the impacts that promotes the behavior intention to user mobile payment so that the consumers can understand thoughtfully the mobile payment purpose and will limit the traditional payment. The most important that they can educate other people such as friends, family, colleagues to have the same thinking and actions toward mobile payment although in Cambodia, the Intellectual level is very low, especially in the countryside. In this case, the role of government and service providers are very important to help them increase their understanding of mobile payment, this research can contribute a small solution to the government plan in developing mobile payment across the country provinces.

There are some limitations to be highlighted although the model is fit with the data when Normed Chisquare is less than 5.0 but CFI and RMSEA do not pass the requirements, but the empirical results are considered to be accepted. It is explained by the underlying relationships in the model but they have not been captured yet. Furthermore, the data is collected from a survey with 200 successful questionnaires. The data quality is heavily depended on the attitude of the respondents who are participated in the survey. Therefore, future researchers should involve more variables and relationships between variables i.e. the relationship between performance expectancy and effort expectancy and the relationship between perceived transaction speed and behavior intention. The survey should be conducted in larger samples in order to reduce the data bias and the application of in-depth interview in order to capture underlying information to further explain for the relationships between variables.

\section{References}

Abadzhmarinova, R. S. (2014). Exploring the effect of speed of purchase on consumers' intention to adopt NFC mobile payments. Thesis. Copenhagen Business School.

Al-Azizi, L., Al-Badi, A. H., \& Al-Zrafi, T. (2018). Exploring the factors influencing employees' willingness to use mobile applications in Oman: Using UTAUT model. Journal of e-Government Studies and Best Practices, 1-27.

Aslam, W., Ham, M., \& Arif, I. (2017). Consumer behavioral intentions towards mobile payment services: An empirical analysis in Pakistan. Market-Trziste, 29(2), 161-176.

Aydin, G., \& Burnaz, S. (2016). Adoption of mobile payment systems: A study on mobile wallets. Journal of Business, Economics and Finance, 5(1), 73-92.

Azam, M. S., \& Imai, K. S. (2009). Vulnerability and poverty in Bangladesh. Chronic Poverty Research Centre Working Paper 141.

Byrne, B. M., \& Van de Vijver, F. J. (2010). Testing for measurement and structural equivalence in largescale cross-cultural studies: Addressing the issue of nonequivalence. International Journal of Testing, 10(2), 107-132.

Byrne, B. M. (2016). Adaptation of assessment scales in cross-national research: Issues, guidelines, and caveats. International Perspectives in Psychology: Research, Practice, Consultation, 5(1), 51.

Beck, T., Demirguc-Kunt, A., \& Peira, M. S. M. (2008). Banking services for everyone? Barriers to bank access and use around the world. The World Bank Economic Review, 22(3), 397-430.

Beck, T., \& Cull, R. (2013). Banking in Africa. Policy Research Working Paper 6684. World Bank Publications.

Bezhovski, Z. (2016). The future of the mobile payment as electronic payment system. European Journal of Business and Management, 8(8), 127-132.

Bui, T. T. H., \& Bui, H. T. (2018). Gamification impact on the acceptance of mobile payment in Ho Chi Minh City, Vietnam. International Journal of Social Science and Economic Research, 3(9), 4822-4837.

Carr. M. (2008). Mobile payment systems and services: An introduction. IDRBT

Capgemini. (2018). Word payments report 2018. Retrieved from https://worldpaymentsreport.com/wp-content/uploads/sites/5/2018/10/World-Payments-Report-2018.pdf.

Chen, X., Carpenter, D., Li, X., Chen, C. C., \& Hung, S-Y. (2018). Why do individuals continue using mobile payments - A qualitative study in China. Proceedings of the 51st Hawaii International Conference on System Sciences. 
Chiang, C. W., Anderson, C., Flores-Saviaga, C., Arenas Jr, E., Colin, F., Romero, M., ... \& Savage, S. (2017, November). Understanding Interface Design and Mobile Money Perceptions in Latin America. In Proceedings of the 8th Latin American Conference on Human-Computer Interaction (p. 5). ACM.

Collins, D., Morduch, J., Rutherford, S., and Ruthven, O. (2009). Portfolios of the poor: How the world's poor live on $\$ 2$ a day. Princeton University Press.

da Costa, G., Monterio, A., \& Baptista, M. (2016). Mobile banking and mobile payment acceptance. Doctorate Program. NOVA Information Management School.

Dimitrii, V. (2018). Determining factors of adoption of digital device wallets by Russian consumers. Thesis. St. Petersburg University.

de Luna, I. R., Montoro-Rios, F., Liebana-Cabanillas, F., \& de Luna, J. G. (2017). NFC technology acceptance for mobile payments: A Brazilian perspective. Revista Brasileira de Gestao de Negocios, 19(63), $82-103$

Doan, N. (2014). Consumer adoption in mobile wallet. The Turku University of Applied Sciences.

Dodgson, M., Gann, D., Wladawsky-Berger, I., Sultan, N., \& George, G. (2015). Managing digital money. Academy of Management Journal, 58(2), pp.325-333.

Ernst \& Young. (2018). Payments insights and opinions volume 19. Retrieved from https://www.ey.com/Publication/vwLUAssets/EY__Payments_nl_vol_19/\$File/ey-payments-nl-vol-19.pdf

Foon, L. K. (2014). Comparison of consumers' behavioral intention towards credit card mobile payment and octopus mobile payment in Hong Kong. Thesis. Hong Kong Baptist University.

Gefen, D., \& Straub, D. W. (2000). The relative importance of perceived ease of use in is adoption: A study of e-commerce adoption. Journal of the Association for Information Systems, 1(8), 1-28.

Havidz, H. L. H., Aima, H. M., Ali, H., \& Iqbal, M. K. (2018). Intention to adopt WeChat mobile payment innovation towards Indonesia citizenship based in China. International Journal of Application or Innovation in Engineering \& Management, 7(6), 105-117.

Husson, T. (2015). The future of mobile wallet lies beyond payments. U.S.A.: Forrester Research Inc.

Jack, W., \& Suri, T. (2014). Risk sharing and transactions costs: Evidence from Kenya's mobile money revolution. The American Economic Review, 104(1), 183-223.

Kumar, K. S., Sivashanmugam, C., \& Venkataraman, A. (2018). Intention to use mobile wallet: Extension of TAM model. Journal of Electronic Systems, 8(1), 27-34.

Lai, P. C. (2017). The literature review of technology adoption models and theories for the novelty technology. Journal of Systems and Technology Management, 14(1), 21-38.

Liebana-Cabanillas, F., de Luna, I. R., \& Montoro-Rios, F. (2017). Intention to use new mobile payment systems: a comparative analysis of SMS and NFC payments. Economic Research-Ekonomska Istrazivanja, 30(1), 892-910.

Lafraxo, Y., Hadri, F., Amhal, H., \& Rossafi, A. (2018). The Effect of Trust, Perceived Risk and Security on the Adoption of Mobile Banking in Morocco. Proceedings of the 20th International Conference on Enterprise Information Systems (ICEIS 2018), 2, 497-502.

Lai, I. K. W. (2013). Traveler acceptance of an app-based mobile tour guide. Journal of Hospitality and Tourism Research, 39(3), 401-432

Mekong Business Initiative. (2018). Report on financial technology (FinTech) in Cambodia. Retrieved from https://www.nbc.org.kh/download_files/others/2 FinTech-in-Cambodia-Presentation-V.1.pdf.

Moya, M. B., Engotoit, B., \& Mayoka, G. K. (2018). Mediating effect of price value on effort expectancy and behavioural intentions to use mobile communication technologies by commercial farmers in Uganda. Journal on Management Studies, 4(2), pp.754-783.

Musa, A., Khan, H. U., \& AlShare, K. A. (2015). Factors influence consumers' adoption of mobile payment devices in Qatar. International Journal of Mobile Communications, 13(6), 1-21.

Okumus, F., Ali, F., Bilgihan, A., \& Ozturk, A. B. (2016). Psychological factors influencing customers' acceptance of smartphone diet apps when ordering food at restaurants. International Journal of Hospitality Management, 72, 67-77.

Oliveira, T., Thomas, M., Baptista, G., \& Camos, F. (2016). Mobile payment: Understanding the determinants of customer adoption and intention to recommend the technology. Computer in Human Behavior, 61, 404-414.

Palau-Saumell, R., Forgas-Coll, S., Sanchez-Garcia, J., \& Robres, E. (2019). User acceptance of mobile apps for restaurants: An expanded and extended UTAUT-2. Sustainability, 11, 1-24. 
Pelletier, A., Khavul, S., and Estrin, S. (2017). Mobile payment services in developing countries: firm capabilities and financial development. International Growth Centre.

Qi, C. (2018). Will Hong Kong consumers embrace mobile payments? Exploring the early adopter's intention to use mobile payment platforms. The Hong Kong Polytechnic University. Retrieved from https://www.fbe.hku.hk/conference/csim2018/assets/files/E2-3.pdf.

Raina, V. K. (2015). Overview of mobile payment: Technologies and security. IGI Global.

Rondan-Catauna, F. J., Arenas-Gaitan, J., \& Ramirez-Correa, P. S. (2015). A comparison of the different versions of popular technology acceptance models: A non-linear perspective. Kybernetes, 44(5), 788780.

Sair, S. A., \& Danish, R. Q. (2018). Effect of performance expectancy and effort expectancy on the mobile commerce adoption intention through personal innovativeness among Pakistani consumers. Pakistan Journal of Commerce and Social Sciences, 12(2), 501-520.

Samaradiwakara, G. D. M. N., and Gunawardena, C. G. (2014). Comparison of existing technology acceptance theories and models to suggest a well improved theory/model. International Technical Sciences Journal, 1(1), 21-36.

Schuh, S., and Stavins, J. (2016). How do speed and security influence consumers' payment behavior? Contemporary Economic Policy, 34(4), 595-613.

Seetharaman, A., Kumar, K. N., Palaniappan, S., \& Weber, G. (2017). Factors influencing behavioural intention to use the mobile wallet in Singapore. Journal of Applied Economics and Business Research, 7(2), 116-136.

Schierz, P. G., Schilke, O., \& Wirtz, B. W. (2010). Understanding consumer acceptance of mobile payment services: An empirical analysis. Electronic Commerce Research and Applications, 9(3), 209-216.

payment services: An empirical analysis. Electronic Commerce Research and Applications, 9(3), 209-216.

Slade, E. L., Dwivedi, Y. K., Piercy, N. C., \& Williams, M. D. (2015). Modeling consumers' adoption intentions of remote mobile payments in the United Kingdom: Extending UTAUT with innovativeness, risk, and trust. Psychology of Marketing, 32, 860-873.

Seng, K., \& Lay, S. H. (2018). Financial inclusion: Are mobile phones helpful in Cambodia? NBC Working Paper Final 19. Retrieved from https://www.nbc.org.kh/download files/research papers/english/NBC Working_Paper_Final 19.11.2018.pdf.

Teo, A-C., Tan, G. W-H., Ooi, K-B., \& Yew, K-T. (2015). The effects of convenience and speed in mpayment. Industrial Management \& Data Systems, 115(2), 311-331.

The Statistics Portal. (2019). Total revenue of global mobile payment market from 2015 to 2019 (in billion U.S. dollars). Retrieved from https://www.statista.com/statistics/226530/mobile-payment-transactionvolume-forecast/.

The World Bank. (2019). Cambodia. Retrieved from http://www.worldbank.org/en/country/cambodia/overview.

The World Bank. (2018). Cambodia - Global Financial Inclusion (Global Findex) Database. Retrieved from https://datacatalog.worldbank.org/dataset/cambodia-global-financial-inclusion-global-findex-database-2017.

Venkatesh, V., Morris, M. G., Davis, G. B., \& Davis, F. D. (2003). User Acceptance of Information Technology: Toward a Unified View. MIS Quarterly, 27(3), 425-478.

Venkatesh, V., Thong, J. Y. L., \& Xu, X. (2012). Consumer acceptance and use of information technology: Extending the Unified Theory of Acceptance and Use of Technology. MIS Quarterly, 36(1), 157-178.

Wang, L., \& Yi, Y. (2012). The impact of use context on mobile payment acceptance: An empirical study in China. In Advances in computer science and education (pp. 293-299). Springer, Berlin, Heidelberg.

Yeh, M. L., and Tseng, Y. L. (2017). The college students' behavior intention of using mobile payments in Taiwan: an exploratory research. Proceedings of IASTEM International Conference, Singapore, $2^{\text {nd }}-3^{\text {rd }}$ January 2017.

Zhou, T. (2013). An empirical examination of continuance intention of mobile payment services. Decision Support Systems, 54(2), 1085-1091.

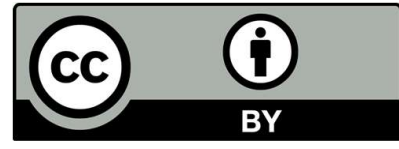

(C) 2019 by the authors; licensee Growing Science, Canada. This is an open access article distributed under the terms and conditions of the Creative Commons Attribution (CCBY) license (http://creativecommons.org/licenses/by/4.0/). 